\title{
Evaluation of selected varieties of yellow lupine and narrow-leaf lupine for colonization by aphids
}

\author{
Ocena podatności wybranych odmian łubinu żółtego \\ i wąskolistnego na zasiedlanie przez mszyce
}

\author{
Przemysław Strażyński ${ }^{1 a}$, Andrzej Bandyk $^{1 \mathrm{~b}}$, Wiktor Bieniewicz ${ }^{2}$, Adam Bartkowski $^{1 \mathrm{a}}$
}

\begin{abstract}
Summary
The field experiments were conducted at the Experimental Station of Variety Evaluation at Głodowo that belongs to Research Centre for Cultivar Testing in Słupia Wielka in 2011-2012. Five yellow lupine varieties (Mister, Perkoz, Lord, Dukat, Parys) and five varieties of narrow-leaf lupine (Karo, Sonet, Mirela, Regent, Bojar) were studied. The same varieties were included in the research carried out in the environmental chamber, under controlled conditions (constant temperature, humidity and photoperiod), in four replications at the Institute of Plant Protection - National Research Institute in Poznań. The aim of this study was to demonstrate the differences in the susceptibility of tested varieties for colonization and development of aphids. As a result of experiments it was found that the pea aphid (Acyrthosiphon pisum Harris) mainly colonized the varieties of yellow lupine, while on the narrow-leaf lupine only a few individuals of this species were recorded. The aphids of the genus Aphis spp. (A. fabae Scop., A. craccivora Koch.) inhabited both lupine species at the same density in the two years of observation. Variety preferences of aphids observed in the field experiments were similar to the results collected from the experiments performed under controlled conditions.
\end{abstract}

Key words: yellow lupine, narrow-leaf lupine, varieties, aphids

\section{Streszczenie}

Doświadczenia polowe prowadzono w Zakładzie Doświadczalnym Oceny Odmian w Głodowie należącym do Centralnego Ośrodka Badania Odmian Roślin Uprawnych w Słupi Wielkiej, w latach 2011-2012. W badaniu wykorzystano pięć odmian łubinu żółtego (Mister, Perkoz, Lord, Dukat, Parys) i pięć odmian łubinu wąskolistnego (Karo, Sonet, Mirela, Regent, Bojar). Na tych samych odmianach prowadzono obserwacje w Instytucie Ochrony Roślin - Państwowym Instytucie Badawczym w Poznaniu, w czterech powtórzeniach w kabinie klimatyzacyjnej, w kontrolowanych warunkach (stała temperatura, wilgotność i fotoperiod). Celem tego badania była próba wykazania różnic w podatności testowanych odmian na zasiedlanie i rozwój mszyc. W wyniku przeprowadzonych obserwacji stwierdzono, że mszyca grochowa (Acyrthosiphon pisum Harris) zasiedlała lepiej odmiany łubinu żółtego, niż łubinu wąskolistnego. Mszyce z rodzaju Aphis spp. (A. fabae Scop., A. craccivora Koch.) w obydwu latach obserwacji, w podobnym stopniu zasiedlały oba gatunki łubinów. Preferencje odmianowe mszyc obserwowane w warunkach polowych były zbliżone do wyników uzyskanych w doświadczeniach w warunkach kontrolowanych.

Słowa kluczowe: łubin żółty, łubin wąskolistny, odmiany, mszyce

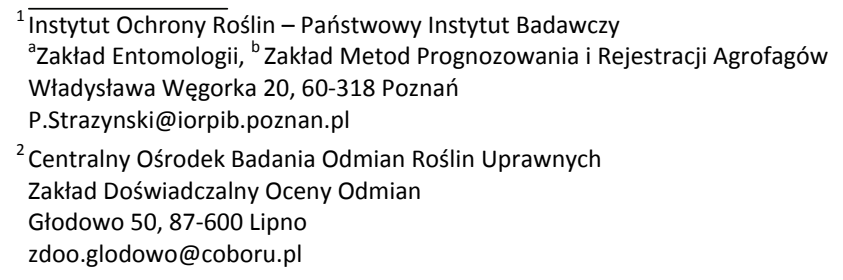




\section{Wstęp / Introduction}

Mszyce (Aphidoidea) stanowią najliczniejszy podrząd wśród pluskwiaków równoskrzydłych i zaliczane są do ważnych gospodarczo szkodników roślin uprawnych, w tym bobowatych (Mrówczyński i wsp. 2006). Zasiedlają praktycznie wszystkie organy roślin, wpływając bezpośrednio na ich wzrost i plonowanie. Istotna jest również pośrednia szkodliwość mszyc, a więc przenoszenie wraz ze śliną groźnych wirusów roślinnych. Zasiedlenie danej rośliny przez mszycę, podjęcie żerowania i rozwoju poprzedza rozpoznanie - głównie barwa. Również czynniki takie, jak: smak, zapach, fenologia rośliny, zawartość aminokwasów i alkaloidów decydują o akceptacji poszczególnych gatunków roślin, ich odmian (Montllor i Tjallingii 1989; Montllor 1991; Berlandier 1996; Leszczyński 1996; Caillauda i Via 2000).

Na łubinach najczęściej występują trzy gatunki mszyc: mszyca grochowa - Acyrthosiphon pisum Harris, 1763, mszyca trzmielinowo-burakowa - Aphis fabae Scop., 1776 oraz mszyca lucerno-grochodrzewowa - A. craccivora Koch., 1854 (Strażyński i Wachowiak 2012).

Celem przeprowadzonych badań była próba wykazania różnic $\mathrm{w}$ podatności testowanych odmian łubinu żółtego i wąskolistnego na zasiedlanie i rozwój mszyc.

\section{Materiały i metody / Materials and methods}

Badania prowadzono w latach 2011-2012. Doświadczenia polowe przeprowadzono w Zakładzie Doświadczalnym Oceny Odmian w Głodowie (województwo kujawsko-pomorskie), należącym do Centralnego Ośrodka Badania Odmian Roślin Uprawnych w Słupi Wielkiej, na pięciu odmianach łubinu żółtego (Mister, Perkoz, Lord, Dukat, Parys) oraz pięciu odmianach łubinu wąskolistnego (Karo, Sonet, Mirela, Regent, Bojar). W sezonie wegetacyjnym 2011 wykorzystano żółte tablice lepowe do monitoringu liczebności uskrzydlonych morf mszyc, które umieszczano nad roślinami (po jednej na każdą odmianę) i wymieniano w tygodniowych odstępach. W sezonie 2012 prowadzono na roślinach tych samych odmian bezpośrednie lustracje co dwa tygodnie. Obejmowały one 100 losowych roślin wybranych po przekątnej pola. Przy opracowywaniu wyników doświadczeń polowych przedstawiono liczebność $A$. pisum, natomiast $A$. fabae i A. craccivora przyjęto łącznie jako rodzaj Aphis spp. Równocześnie w Instytucie Ochrony Roślin - Państwowym Instytucie Badawczym w Poznaniu, w kabinie klimatyzacyjnej, w warunkach kontrolowanych $\left(19^{\circ} \mathrm{C}\right.$, $70 \% \mathrm{RH}$ - relative humidity, 14:10 L:D) testowano te same odmiany łubinów pod kątem zasiedlania ich przez dwa gatunki mszyc. W tym celu na każdą izolowaną roślinę w fazie trzeciego liścia $(\mathrm{BBCH} 23)$ nanoszono po trzy larwy mszyc $A$. pisum w stadium $\mathrm{L}_{2}$, pozyskane $\mathrm{z}$ hodowli na grochu i $A$. fabae, pochodzącą z hodowli na trzmielinie. Doświadczenie prowadzono w 4 powtórzeniach. W każdym powtórzeniu na każdej pojedynczej roślinie prowadzono obserwacje co 3, 5, 7 i 14 dni, określając liczebność mszyc.

\section{Wyniki i dyskusja / Results and discussion}

W wyniku doświadczeń polowych stwierdzono, że A. pisum zasiedlała głównie rośliny łubinu żółtego, odpowiednio 86,3\% w 2011 r. i 95,6\% w 2012 r., a odmianami najchętniej zasiedlanymi były Lord i Perkoz. Na odmianach łubinu wąskolistnego notowano jedynie pojedyncze osobniki tego gatunku. Mszyce z rodzaju Aphis spp. w obydwu latach obserwacji w podobnym stopniu zasiedlały obydwa gatunki łubinów. W 2011 r. stwierdzono mniejszą liczebność mszyc $z$ uwagi na rejestrowanie wyłącznie morf uskrzydlonych (tab. 1). W bezpośrednich lustracjach prowadzonych w sezonie 2012 uwzględniano wszystkie morfy (tab. 2).

Tabela 1. Liczba odłowionych z użyciem żółtych tablic uskrzydlonych mszyc na odmianach łubinu żółtego i wąskolistnego w Głodowie w $2011 \mathrm{r}$.

Table 1. The number of winged aphids caught using yellow sticky cards on varieties of yellow lupine and narrow-leaf lupine in Głodowo in 2011

\begin{tabular}{|c|c|c|c|c|c|c|c|c|c|c|c|c|c|}
\hline \multirow{3}{*}{\multicolumn{2}{|c|}{$\begin{array}{l}\text { Odmiana } \\
\text { Variety }\end{array}$}} & \multicolumn{10}{|c|}{ Data-Date } & \multirow{2}{*}{\multicolumn{2}{|c|}{$\begin{array}{l}\text { Suma } \\
\text { Total }\end{array}$}} \\
\hline & & \multicolumn{2}{|c|}{25.05} & \multicolumn{2}{|c|}{2.06} & \multicolumn{2}{|c|}{9.06} & \multicolumn{2}{|c|}{16.06} & \multicolumn{2}{|c|}{23.06} & & \\
\hline & & A & B & A & B & A & B & $\mathrm{A}$ & B & $\mathrm{A}$ & B & A & B \\
\hline \multirow{5}{*}{ 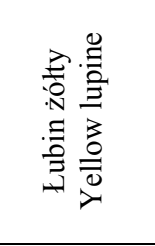 } & Mister & 1 & 1 & 4 & 3 & 7 & 5 & 10 & 6 & 10 & 8 & 32 & 23 \\
\hline & Perkoz & 2 & 2 & 4 & 5 & 7 & 7 & 11 & 14 & 11 & 10 & 35 & 38 \\
\hline & Lord & 3 & 2 & 3 & 5 & 10 & 9 & 13 & 14 & 14 & 15 & 40 & 45 \\
\hline & Dukat & 0 & 2 & 2 & 4 & 4 & 8 & 5 & 11 & 9 & 11 & 18 & 36 \\
\hline & Parys & 1 & 2 & 3 & 5 & 5 & 6 & 7 & 9 & 10 & 10 & 26 & 32 \\
\hline \multirow{5}{*}{ 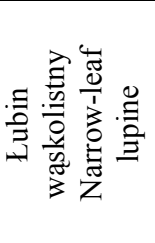 } & Karo & 0 & 2 & 0 & 4 & 1 & 7 & 1 & 11 & 2 & 12 & 4 & 36 \\
\hline & Sonet & 0 & 3 & 1 & 8 & 2 & 11 & 3 & 9 & 3 & 12 & 9 & 43 \\
\hline & Mirela & 1 & 3 & 1 & 8 & 1 & 13 & 2 & 12 & 1 & 11 & 6 & 47 \\
\hline & Regent & 0 & 3 & 1 & 5 & 2 & 14 & 1 & 16 & 2 & 16 & 6 & 54 \\
\hline & Bojar & 1 & 2 & 1 & 4 & 0 & 10 & 1 & 11 & 2 & 10 & 5 & 37 \\
\hline
\end{tabular}

A - Acyrthosiphon pisum, B - Aphis spp. 
Tabela 2. Liczebność mszyc na odmianach łubinu żółtego i wąskolistnego w Głodowie w 2012 r.

Table 2. The number of aphids on varieties of yellow lupine and narrow-leaf lupine in Głodowo in 2012

\begin{tabular}{|c|c|c|c|c|c|c|c|c|c|c|c|}
\hline \multirow{3}{*}{\multicolumn{2}{|c|}{$\begin{array}{l}\text { Odmiana } \\
\text { Variety }\end{array}$}} & \multicolumn{8}{|c|}{ Data-Date } & \multirow{2}{*}{\multicolumn{2}{|c|}{$\begin{array}{l}\text { Suma } \\
\text { Total }\end{array}$}} \\
\hline & & \multicolumn{2}{|c|}{18.05} & \multicolumn{2}{|c|}{2.06} & \multicolumn{2}{|c|}{15.06} & \multicolumn{2}{|c|}{28.06} & & \\
\hline & & A & B & A & B & A & B & A & B & A & B \\
\hline \multirow{5}{*}{ 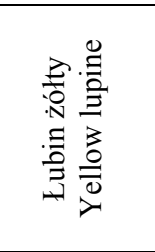 } & Mister & 6 & 4 & 12 & 12 & 22 & 22 & 31 & 30 & 71 & 58 \\
\hline & Perkoz & 9 & 8 & 16 & 19 & 29 & 31 & 38 & 36 & 92 & 94 \\
\hline & Lord & 6 & 8 & 18 & 17 & 29 & 33 & 42 & 35 & 94 & 93 \\
\hline & Dukat & 7 & 7 & 11 & 14 & 16 & 28 & 30 & 31 & 64 & 80 \\
\hline & Parys & 7 & 8 & 14 & 14 & 20 & 30 & 31 & 29 & 72 & 81 \\
\hline \multirow{5}{*}{ 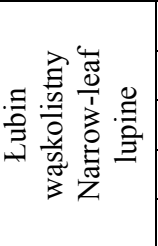 } & Karo & 0 & 6 & 1 & 13 & 0 & 28 & 1 & 39 & 2 & 86 \\
\hline & Sonet & 1 & 8 & 1 & 14 & 1 & 31 & 1 & 38 & 4 & 91 \\
\hline & Mirela & 1 & 7 & 2 & 14 & 1 & 30 & 1 & 32 & 6 & 83 \\
\hline & Regent & 1 & 8 & 2 & 18 & 0 & 31 & 2 & 39 & 5 & 98 \\
\hline & Bojar & 0 & 5 & 1 & 10 & 1 & 27 & 2 & 21 & 4 & 63 \\
\hline
\end{tabular}

A - Acyrthosiphon pisum, B - Aphis spp.

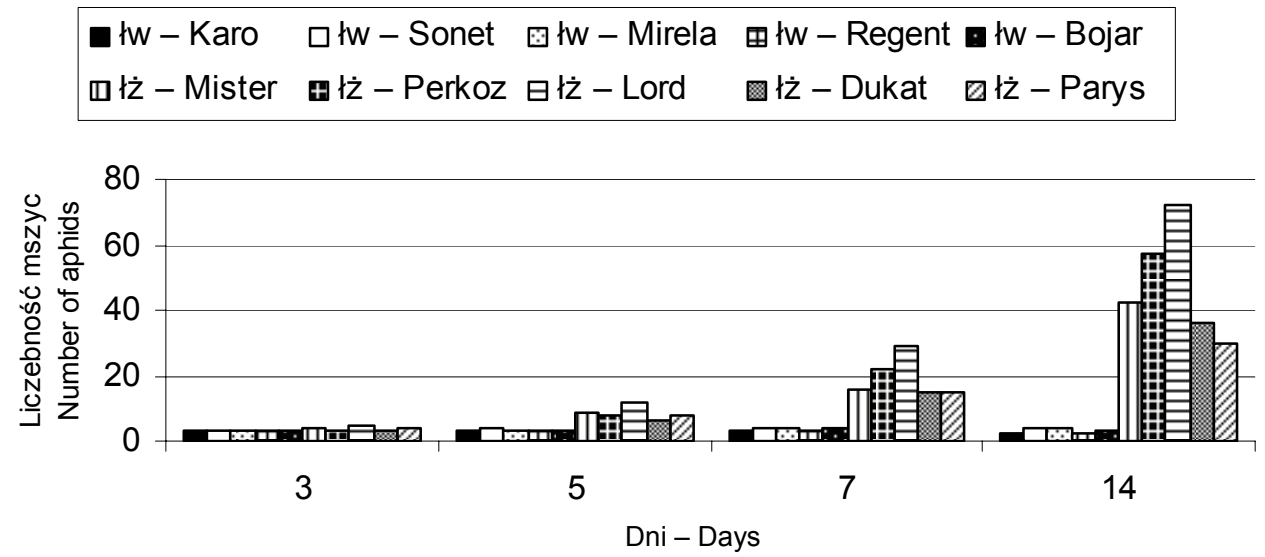

Rys. 1. Dynamika liczebności A. pisum na odmianach łubinu żółtego (łż) i wąskolistnego (łw) w warunkach kontrolowanych (wartości uśrednione)

Fig. 1. Number dynamics of $A$. pisum on varieties of yellow lupine (łż) and narrow-leaf lupine (łw) under controlled conditions (average values)

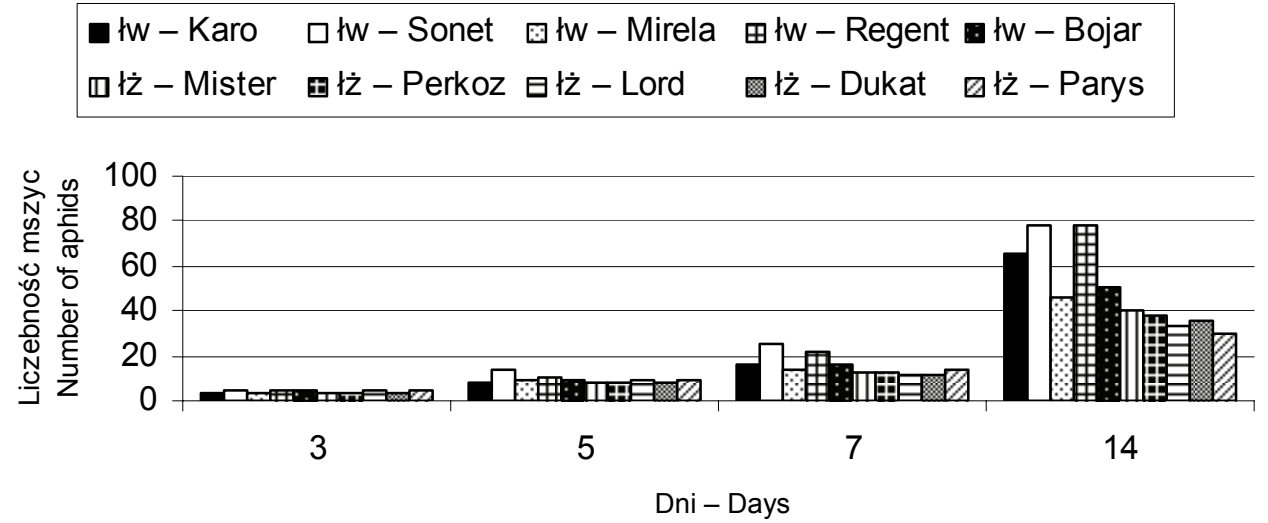

Rys. 2. Dynamika liczebności A. fabae na odmianach łubinu żółtego (łż) i wąskolistnego (łw) w warunkach kontrolowanych (wartości uśrednione)

Fig. 2. Number dynamics of $A$. fabae on varieties of yellow lupine (łż) and narrow-leaf lupine (łw) under controlled conditions (average values) 
A. pisum jest bardziej wyspecjalizowanym pokarmowo gatunkiem niż $A$. fabae, a zakres jej roślin żywicielskich jest węższy i ograniczony do rodziny Fabaceae. W warunkach kontrolowanych wykazano, że najbardziej podatne na żerowanie $A$. pisum były odmiany łubinu żółtego: Mister, Perkoz i Lord (rys. 1), natomiast A. fabae preferowała odmiany łubinu wąskolistnego: Karo, Sonet i Regent (rys. 2). W doświadczeniu zaobserwowano także, że mszyce obydwu gatunków preferują głównie wierzchołkowe części roślin, zarówno łubinu żółtego, jak i wąskolistnego. A. pisum żerowała wyłącznie na liściach, natomiast $A$. fabae zarówno na liściach, jak i pędach.

We wcześniejszych badaniach również wykazywano, że łubin wąskolistny nie jest rośliną akceptowaną przez A. pisum, na której rozwijała się słabo lub wcale (Kordan i wsp. 2008; Słomka i Kordan 2010). Wcześniejsze dokładne analizy parametrów żerowania wykazały, że na odmianie łubinu wąskolistnego Karo nie stwierdzano fazy floemowej podczas penetracji tkanek przez A. pisum. Notowano natomiast trzykrotnie większą liczbę krótkich w stosunku do kontroli nakłuć, nie zakończonych żerowaniem (Wróblewska i wsp. 2012). Autorzy podkreślają różnice $\mathrm{w}$ składzie chemicznym soków komórkowych poszczególnych odmian, zlokalizowanych zarówno w soku floemowym, jak i tkankach pozafloemowych oraz wskazują we wnioskach na możliwość ich negatywnego oddziaływania na żerowanie mszyc. W łubinie żółtym i wąskolistnym zawartość podstawowych składników odżywczych jest różna, co mogło wpływać na stopień zasiedlania przez obydwa gatunki mszyc. Duża zawartość angustifoliny, dehydrolupaniny oraz 13-OH lupaniny w hubinie wąskolistnym ogranicza lub całkowicie hamuje rozwój mszyc, natomiast mniejsze stężenie alkaloidów w łubinie żółtym umożliwia mszycom żerowanie, co może mieć wpływ na plonowanie roślin (Kordan 2004, 2006; Philippi i wsp. 2012). Poziom akceptacji danej rośliny może także wynikać z jej budowy morfologicznej, szczególnie stopnia omszenia liści (Boczek 1992).

\section{Wnioski / Conclusions}

1. Rozwój mszyc, a tym samym zakres ich szkodliwości, jest ściśle powiązany $\mathrm{z}$ gatunkiem i odmianą rośliny żywicielskiej oraz jej fenologią.

2. A. pisum, w odróżnieniu od mszyc z rodzaju Aphis, nie stanowiła potencjalnego zagrożenia dla testowanych odmian łubinu wąskolistnego.

3. Preferencje odmianowe mszyc zaobserwowane w warunkach polowych były zbliżone do wyników uzyskanych w badaniach prowadzonych w warunkach kontrolowanych.

\section{Literatura / References}

Berlandier F. 1996. Alkaloid level in narrow-leaf lupin, Lupinus angustifolius, influences green peach aphid reproductive performance. Entomol. Exp. Appl. 79: 19-24.

Boczek J. 1992. Niechemiczne metody zwalczania szkodników roślin. Wyd. SGGW, Warszawa, 243 ss.

Caillauda C.M., Via S. 2000. Specialized feeding behavior influence both ecological specialization and assortative mating in sympatric host races of pea aphids. Am. Nat. 156: 606-621.

Kordan B. 2004. Assessment of damage caused to lupine plants by pea aphids (Acyrthosiphon pisum Harris). Aphids and Other Hemipterous Insects 10: 61-67.

Kordan B. 2006. Porównanie łubinu żółtego (Lupinus luteaus L.) i wąskolistnego (Lupinus angustifolius L.) jako roślin żywicielskich mszycy grochowej (Acyrthosiphon pisum Harris). Wyd. UWM, Olsztyn, 76 ss.

Kordan B., Gabryś B., Dancewicz K., Lahuta L.B., Piotrowicz-Cieślak A., Rowińska E. 2008. European yellow lupine, Lupinus luteus, and narrow-leaf lupine, Lupinus angustifolius, as hosts for the pea aphid, Acyrthosiphon pisum. Entomol. Exp. Appl. 128: $139-146$.

Leszczyński B. 1996. Kurs praktyczny w zakresie chemicznych interakcji owad-roślina na przykładzie mszyc (Aphidoidae). Wyd. Nauk. WSRP, Siedlce: 16-36.

Montllor C.B. 1991. The influence of plant chemistry an aphids feeding behavior. p. 125-173. In: "Insect-Plant Interactions" (E. Bernays, ed.). CRC Press, London, 438 pp.

Montllor C.B., Tjallingii W.F. 1989. Stylet penetration by two aphid species on susceptible and resistance lettuce. Entomol. Exp. Appl. 52: $103-111$.

Mrówczyński M., Wachowiak H., Pruszyński G. 2006. Zagrożenie upraw małoobszarowych przez szkodniki i metody ochrony. [Pest control in minor crops]. Prog. Plant Prot./Post. Ochr. Roślin 46 (1): 99-107.

Philippi J., Schliephake E., Ordon F. 2012. Penetration behavior of different aphid species on Lupinus angustifolius L. genotypes. Nachwuchswissenschaftlerforum/Young Scientists Meeting. Berichte aus dem Julius Kühn-Institut 167, p. 45.

Słomka W., Kordan B. 2010. Bobowate (Fabaceae) jako siedlisko rozwoju mszycy grochowej (Acyrthosiphon pisum Harris). [Papilionaceae as a habitat for the development of pea aphid (Acyrthosiphon pisum Harris)]. Prog. Plant Prot./Post. Ochr. Roślin 50 (4): $1747-1751$.

Strażyński P., Wachowiak H. 2012. Ograniczanie strat powodowanych przez szkodniki. s. 44-55. W: „Metodyka integrowanej ochrony łubinu wąskolistnego, żółtego i białego" (R. Krawczyk, M. Mrówczyński, red.). Inst. Ochr. Roślin - PIB, Poznań, 131 ss.

Wróblewska A., Dancewicz K., Gabryś B., Kordan B. 2012. Rejestracja EPG zachowania mszycy grochowej (Acyrthosiphon pisum Harris) podczas penetracji kłujki na wybranych odmianach łubinu żółtego (Lupinus luteus L.) i wąskolistnego (Lupinus angustifolius L.). [EPG-registered probing behaviour of the pea aphid (Acyrthosiphon pisum Harris) on selected varietes of yellow lupin (Lupinus luteus L.) and narrow-leaved lupin (Lupinus angustifolius L.)]. Prog. Plant Prot./Post. Ochr. Roślin 52 (2): 244-247. 